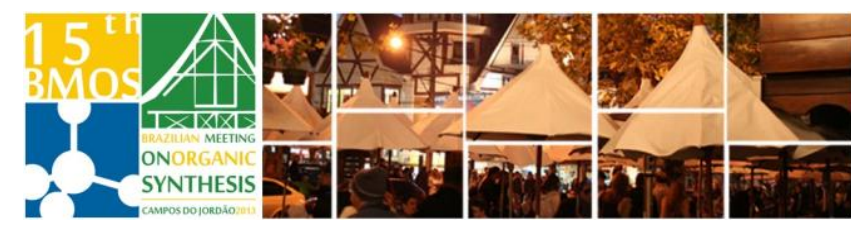

\title{
Study toward the synthesis of $(R)-(-)$-aporphine
}

\section{Givago P. Perecim and Cristiano Raminelli*}

Instituto de Ciências Ambientais, Químicas e Farmacêuticas, Universidade Federal de São Paulo, Diadema, SP, Brazil *raminelli@unifesp.br

Keywords: benzyne chemistry, (R)-(-)-aporphine, total synthesis

\section{INTRODUCTION}

In view of the considerable importance of the benzyne chemistry in reactions of insertion into sigma bonds and cycloaddition reactions, which have been widely used in the synthesis of bioactive natural products ${ }^{1}$ and in preparations of functional materials, $^{2}$ we decided to accomplish the total synthesis of $(R)-(-)$-aporphine (1), using as key step the [4+2] cycloaddition reaction, followed by spontaneous dehydrogenation, between methyleneisoquinoline (4) and benzyne (8), generated from 2-(trimethylsilyl)phenyl triflate (9), under mild reaction conditions. ${ }^{1,3,4}$

\section{RESULTS AND DISCUSSION}

Our approach to obtain (R)-(-)-aporphine (1) was based on the retrosynthetic analysis outlined in Scheme 1.

Scheme 1. Retrosynthetic analysis for (R)-(-)-aporphine (1).

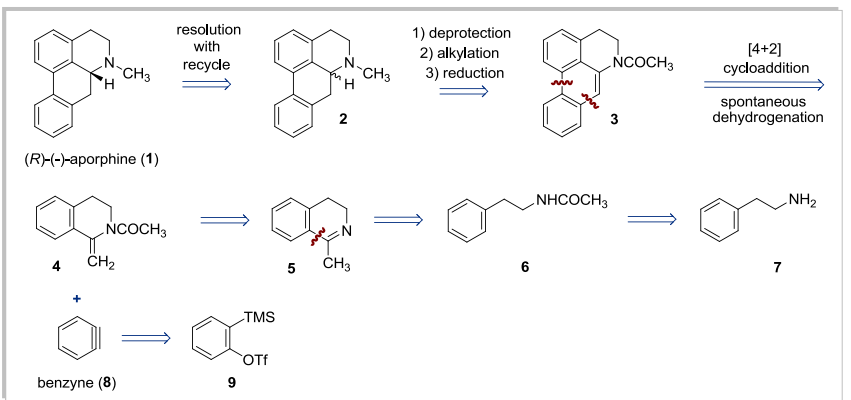

We started the synthesis of the aporphine alkaloid $\mathbf{1}$, by the acetylation reaction of 2-phenethylamine (7), with excess of acetic anhydride, resulting in the formation of $N$-phenethylacetamide (6) in quantitative yield. Next, the reaction of the amide 6 with phosphorus oxychloride and phosphorus pentoxide, led to the formation of 1-methyl-3,4dihydroisoquinoline (5) also in quantitative yield. The protection of the compound 5 with acetic anhydride in pyridine gave 2-acetyl-1-methylene-1,2,3,4tetrahydroisoquinoline (4), however, this reaction is being optimized. Afterwards, we intend to perform the [4+2] cycloaddition reaction between the compound 4 and the benzyne precursor 9 (Scheme 2).
The optimization of yield for the formation of the compound 3 will be carried out and the synthesis of $(R)$-(-)-aporphine (1) will be completed from the intermediate 10 by well-known reactions of reduction $^{5}$ and resolution ${ }^{6}$ shown in Scheme 2.

Scheme 2. Synthetic rote for $(R)-(-)$-aporphine (1).

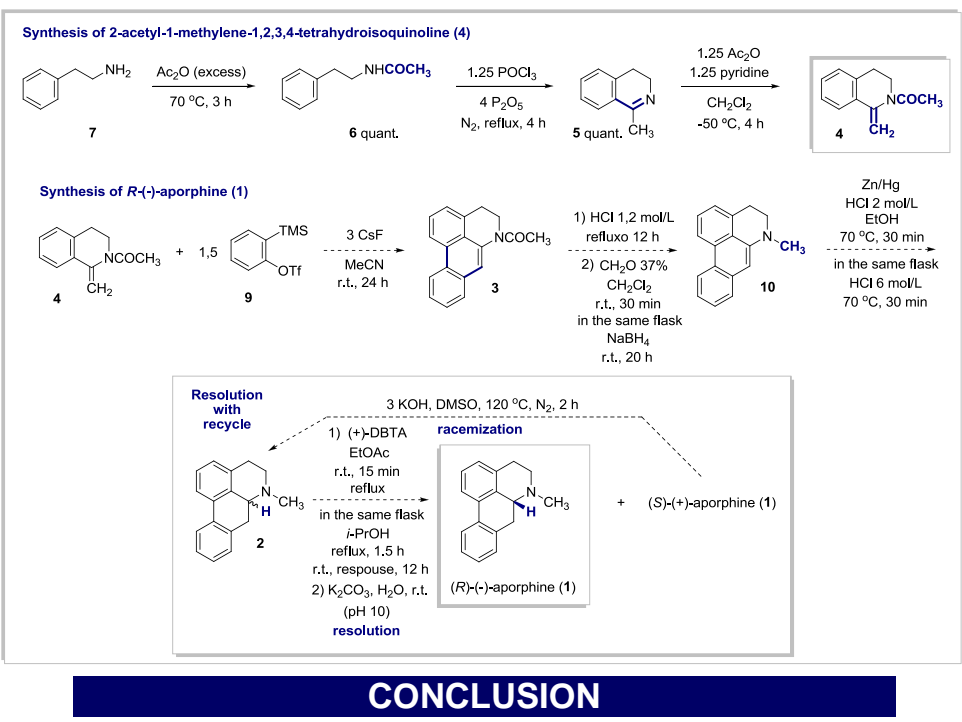

We wish to develop the total synthesis of alkaloid aporphine named (R)-(-)-aporphine (1) employing strategy which involves as key step the [4+2] cycloaddition reaction between 1-methylene-1,2,3,4tetrahydroisoquinoline (4) and the benzyne precursor (9).

\section{ACKNOWLEDGEMENTS}

We gratefully acknowledge CNPq and FAPESP for financial support and CAPES for the scholarship of G.P.P.

\section{REFERENCES}

${ }^{1}$ (a) Tadross, P. M.; Stoltz, B. M. Chem. Rev. 2012, 112, 3550. (b) Gampe, C. M.; Carreira, E. M. Angew. Chem., Int. Ed. 2012, 51, 3766.

${ }^{2}$ (a) Lu, X.; Nikawa, H.; Tsuchiya, T.; Akasaka, T.; Toki, M.; Sawa, H.; Mizorogi, N.; Nagase, S. Angew. Chem., Int. Ed. 2010, 49, 594. (b) Shen, Y.-M.; Grampp, G.; Leesakul, N.; Hu, H.-W.; Xu, J.-H. Eur. J. Org. Chem. 2007, 3718.

${ }^{3}$ Atanes, N.; Castedo, L.; Guitián, E.; Saá, C.; Saá, J. M.; Suau, R. J. Org. Chem. 1991, 56, 2984.

${ }^{4}$ Atanes, N.; Castedo, L.; Cobas, A.; Guitián, E.; Saá, C.; Saá, J. M. Tetrahedron 1989, 45, 7947.

${ }^{5}$ Cava, M. P.; Stern, P.; Wakisaka, K. Tetrahedron 1973, 29, 2245.

${ }^{6}$ Shi, X.-X.; Ni, F.; Shang, H.-X.; Yan, M.-L.; Su, J.-Q. Tetrahedron: Asymmetry 2006, 17, 2210. 